\title{
RESOLUÇÃO DE CONFLITOS: CONCEPÇÕES E PRÁTICAS DE PROFESSORES DOS ANOS INICIAIS DO ENSINO FUNDAMENTAL
}

\author{
Júlia Neves Ferreira ${ }^{1}$, Stephanie Lee Basile Barboza Caseiro ${ }^{2}$, Luciana Aparecida Nogueira da Cruz ${ }^{1}$ \\ ${ }^{1}$ Mestranda do Programa Multidisciplinar Interunidades “Ensino e Processos Formativos” (UNESP), campus de São José do Rio Preto/Ilha Solteira e
Jaboticabal. E-mail: julia.nevesf@yahoo.com.br.
${ }^{2}$ Docente do Colégio Coeso.
${ }^{3}$ Doutora em Educação pela Universidade Estadual Paulista (UNESP), campus de Marília. Docente do Departamento de Educação da Universidade
Estadual Paulista (UNESP), campus de São José do Rio Preto.
}

\section{RESUMO}

Pesquisas que abordam o tema conflitos na escola têm sido cada vez mais comuns, pois é um assunto que desperta muitas dúvidas. Há educadores que não sabem como lidar com os conflitos e muitos acreditam que resolver as desavenças não faz parte da sua função, demonstrando desconhecer a prática da mediação baseada na reciprocidade como real possibilidade de intervenção. Dessa forma, o presente estudo objetivou identificar as estratégias de intervenção e os tipos de sanções utilizadas na resolução de conflitos por professores dos anos iniciais do Ensino Fundamental de duas escolas que trabalham com metodologias pedagógicas distintas. Buscou-se também verificar se a conduta dos educadores nessa prática corrobora com o desenvolvimento da heteronomia ou autonomia moral dos alunos, tendo como base a teoria da moralidade de Jean Piaget. Como método utilizou-se de observação e entrevista estruturada. Responderam a entrevista um total de dez professores de ambas escolas. Os resultados encontrados indicam que os docentes se deparam constantemente com conflitos em seu trabalho, mas nem sempre lidam com eles de forma à desenvolver autonomia moral de seus alunos, prevalecendo a autoridade e a imposição de soluções rápidas para o ocorrido, muitas vezes tomando os conflitos para si, atitudes que tendem a reforçar a heteronomia. Dessa forma, concluímos que a maneira como os professores lidam com os conflitos, de forma recíproca com predomínio das relações de respeito mútuo ou de forma coercitiva com predomínio de sanções expiatórias e o ambiente sociomoral promovido pela escola, interferem significativamente na construção da moral infantil.

Palavras-chave: Resolução de conflitos; Desenvolvimento moral; Ensino Fundamental; Anos Iniciais; Moralidade.

\section{CONFLICT RESOLUTION: CONCEPTIONS AND PRACTICES OF ELEMENTARY YEARS TEACHERS}

\begin{abstract}
Researches that addresses the issue of conflict in school has been increasingly common, as it is a subject that raises many doubts. There are educators who do not know how to deal with conflicts and many of them believe that resolving disputes is not part of their function, showing that they do not know the practice of mediation based on reciprocity as a real possibility of intervention. Thus, the present study aimed to identify the intervention strategies and the types of sanctions used in the resolution of conflicts by teachers of the initial years of Elementary Education of two schools that work with different pedagogical methodologies. It was also sought to verify if the conduct of the educators in this practice corroborates with the development of the students' moral heteronomy or moral autonomy, based on Jean Piaget's theory of morality. As method, it was used observation and structured interview. A total of ten teachers from both schools answered the interview. The results indicate that the teachers are constantly confronted with conflicts in their work, but they do not always deal with them in order to develop the moral autonomy of their students, prevailing some authority and imposing quick solutions to what happened, often taking the conflicts for themselves, the type of attitudes that tend to reinforce heteronomy. Thus, we conclude that the way teachers deal with conflicts, reciprocally with predominance of relations of mutual respect or coercive way with the predominance of expiatory sanctions and the sociomoral environment promoted by the school, significantly interfere in the construction of child morals.

Keywords: Conflicts resolution; Moral development; Elementary School; Primary years; Morality.
\end{abstract}




\section{INTRODUÇÃO}

Os conflitos são inevitáveis e naturais na convivência entre as pessoas, pois são inerentes às relações humanas, visto que, a diversidade e divergência de crenças e opiniões geram discordâncias e atritos entre os indivíduos. Em se tratando especificamente do ambiente escolar, local onde normalmente se empreendem esforços para manter a ordem e a disciplina, notamos constantemente situações conflituosas entre todos que participam de tal contexto. Entretanto, muitas vezes, os conflitos são percebidos por gestores e professores como prejudiciais ao desenvolvimento dos alunos e ao bom andamento das aulas. Não é exagero dizer que prevalece na maioria das escolas um ambiente coercitivo e autoritário, onde exige-se dos alunos que sejam passivos e obedientes. Educadores encaram os conflitos como situações nocivas e prejudiciais, e como são acontecimentos recorrentes, suscitam muitas dúvidas em como lidar com eles, também há aqueles que acreditam não fazer parte da sua função de educador lidar com e auxiliar a criança na resolução dos conflitos.

Estudiosos em psicologia moral, como Vinha, (2000), Tognetta (2009) e Licciardi et al. (2011) afirmam que os conflitos devem ser vistos como situações necessárias à aprendizagem e ao desenvolvimento moral das crianças, uma vez que dá à elas a oportunidade de aprenderem sobre si, sobre os outros e sobre as normas sociais, além de influenciar na construção de valores e princípios. À vista disso, a presente pesquisa buscou identificar como professores lidam com situações conflituosas no ambiente escolar e como as intervenções utilizadas por eles nas tentativas de resolução das mesmas influenciam no desenvolvimento moral infantil.

Vicentin (apud LICCIARDI et al., 2011) destaca que muitos educadores argumentam, ainda hoje, que o papel de educar moralmente é da família acreditando que os pais devem ensinar aos seus filhos, desde o nascimento, o que é certo e errado. Desse modo, demonstram desconhecer a importância do papel da escola na formação moral das crianças. Nesse sentido, Licciardi et al. (2011) apontam que os educadores desempenham um papel essencial na vida dos alunos, sendo também responsáveis por sua formação moral e afetiva. Consideram que o desenvolvimento moral é um processo em construção permanente e a escola, se considerar os conflitos como fator de desequilíbrio para uma autorregulação, pode ser um agente facilitador para este desenvolvimento.

$\mathrm{Na}$ maioria das escolas os conflitos recorrentes em sala de aula são encarados pelos professores como um problema que necessita de algum tipo de punição para serem solucionados, não levando em consideração que as relações estabelecidas no ambiente escolar influenciam direta e significativamente no processo de construção de valores e da autonomia moral. Frequentemente tentam evitar ou conter os conflitos usando de sua autoridade para intervir de maneira autoritária na resolução do problema. Dessa forma, acabam favorecendo a manutenção da heteronomia e perdendo a oportunidade de construir um ambiente favorável ao desenvolvimento de relações cooperativas em que prevaleçam valores e regras, importantes para um bom convívio social ético e democrático. Por outro lado, à luz do construtivismo essas situações são vistas como naturais e necessárias ao desenvolvimento da criança, além de serem consideradas como oportunidades favoráveis para que valores e regras sejam trabalhados, favorecendo a formação de indivíduos autônomos.

Como apontado por Piaget (1975/1985, apud DEVRIES; ZAN, 1998), o conflito deve ser considerado o fator mais influente na aquisição de novas estruturas de conhecimento pois, quando desencadeado, o sujeito pode ser motivado, pelo desequilíbrio causado, a refletir sobre maneiras distintas de restabelecer a reciprocidade, ou seja, a pensar na perspectiva do outro e não somente na sua, resolvendo-o de forma justa e positiva.

Vinha (2000) considera que em seu trabalho diário com as crianças, o professor defronta-se constantemente com pequenas dificuldades, problemas repentinos, momentos de crises e desavenças, ocorrências cotidianas que exigem uma conduta por parte do adulto e a maneira que ela lida com tais situações, interfere na construção do julgamento moral da criança. Dessa forma, Nunes (2011) destaca que a mediação, pautada na reciprocidade e em princípios morais, permite a solução de conflitos rotineiros através do diálogo e da compreensão, possibilitando formas criativas de transformação dos conflitos em oportunidades de crescimento e de mudanças nos envolvidos, trazendo-lhes lições duradouras para o crescimento interior. 
Diante de tais considerações, essa pesquisa objetivou investigar as concepções sobre conflitos, regras e sanções de professores dos anos iniciais do Ensino Fundamental de duas escolas que trabalham com metodologias pedagógicas diferentes. E identificar as estratégias, intervenções e os tipos de sanções utilizadas por eles nas resoluções de conflitos entre as crianças, verificando se tais aspectos utilizados corroboram com o desenvolvimento da heteronomia ou da autonomia moral dos alunos segundo a teoria da moralidade de Jean Piaget (1932/1994).

\section{DESENVOLVIMENTO}

Em sua obra "O juízo moral da criança", base para o desenvolvimento deste estudo, Jean Piaget (1932/1994), importante teórico da psicologia desenvolvimentista, publicou suas pesquisas sobre desenvolvimento moral. 0 pesquisador suíço estudou a moralidade humana, buscando compreender o juízo moral de crianças por meio de investigações empíricas referentes à evolução das noções de regras, do juízo moral e da justiça. Ele concluiu e descreveu a existência de duas tendências morais: heteronomia e autonomia.

Um ponto de grande relevância destacado pelo autor em sua obra refere-se ao tipo de relação interindividual estabelecida que pode ser de coação ou "moral do dever" que conduz à heteronomia, e de cooperação ou "moral do bem" que conduz à autonomia. Piaget (1932/1994) considerou a primeira como um tipo de relação assimétrica pautada no respeito unilateral, em que as leis são impostas e a criança aceita do adulto um certo número de ordens às quais deve submeter-se quaisquer que sejam as circunstâncias, tendo a moral como sinônimo de autoridade; enquanto a segunda teria por princípio o respeito mútuo e a solidariedade, que acentua a autonomia da consciência, onde a criança passa a pensar a moral pela reciprocidade. Tal relação é considerada por Piaget como um importante elemento para que o sujeito construa o pensamento autônomo.

Em seus estudos, o autor também definiu dois tipos de sanções: as expiatórias e as por reciprocidade. As sanções expiatórias têm como objetivo fazer com que o indivíduo que infringiu uma regra sofra castigos ou punições pelo seu erro. Nesse aspecto, os adultos punem considerando a consequência do ato e não sua real intencionalidade e a criança acaba recebendo punições desproporcionais a sua falta, não contribuindo para a compreensão efetiva da regra. É necessário, apenas, que haja proporcionalidade entre o sofrimento imposto e a gravidade da falta, sendo uma sanção baseada na repressão. Esse tipo de sanção é a mais comum em ambientes coercitivos.

Já as sanções por reciprocidade têm como principal característica uma relação natural e lógica com o ato a ser sancionado fazendo com que a criança compreenda as consequências do seu ato (VINHA, 2000). Nesse tipo de sanção há relação entre a falta cometida e o tipo de punição, contribuindo para que as crianças entendam a razão de existirem determinadas regras, além de contribuir na formação da autonomia. Tognetta (2009, p. 101) afirma que "é preciso o uso de sanções por reciprocidade. Os castigos levam ao medo da autoridade que, por sua vez, contribui para que a criança permaneça heterônoma: ela obedece à fonte da regra e não ao princípio gerador."

As pessoas guiadas pela heteronomia são controladas pelo respeito unilateral e não consideram as sanções por reciprocidade como um castigo, uma vez que, a reparação de algum dano é vista como uma consequência natural de seu ato e não como uma punição. Consideram justas as sanções expiatórias, pois, para elas, é por meio do "castigo" que se reestabelece os vínculos abalados. Já os indivíduos que são guiados pela autonomia, passam a compreender que as regras existem em função dos princípios e da necessidade de regular a convivência humana, consideram justas as sanções por reciprocidade, tendo suas ações conduzidas pelo princípio da equidade. Assim, a criança passa a ter condições intelectuais de conceber a justiça como uma forma superior de reciprocidade, não compreendendo mais os direitos iguais dos indivíduos sem considerar a situação particular de cada um.

[...] ser autônomo significa compreender que as regras existem em função de uma necessidade, tenhamos alguém cobrando-as ou não. 0 sujeito autônomo, portanto, é aquele que legitima a regra como dever interiorizado que serve tanto para ele como para qualquer outro 
(LEME; $\quad$ TOGNETTA; VICENTIN, 2013, p.49).

Dessa forma, as relações estabelecidas entre as crianças e o meio que convivem, tanto no ambiente escolar quanto no familiar e na sociedade em geral, tendem a influenciar significativamente na construção da moral, uma vez que é por meio das interações que as crianças passam a conhecer as normas que são aceitas ou não por cada grupo social, e, como estão em constante desenvolvimento, passam a formar gradativamente sua consciência moral. Isso significa que, em ambientes escolares cooperativos, pautados em relações democráticas, onde prevalecem sanções por reciprocidade, respeito mútuo e as regras são construídas pelo grupo, as crianças têm condições mais adequadas para desenvolverem a autonomia moral, pois lhes é dado a oportunidade e a liberdade para escolhas e tomada de decisões.

\section{METODOLOGIA}

Para a realização do presente estudo, que se caracteriza por uma pesquisa de campo qualitativa, foram selecionados dois ambientes escolares que utilizam metodologias pedagógicas distintas. A escolha das duas escolas se deu pelas suas características.

\section{Caracterização das escolas}

A Escola A, trata-se de uma instituição particular, de período parcial com cerca de 500 alunos matriculados nos Anos Iniciais do Ensino Fundamental distribuídos em 20 salas de aula que vão do 1 음 ao 5 o ano. Seu plano pedagógico é baseado na abordagem construtivista, a maioria das salas de aula são organizadas em fileiras e as avaliações são na forma de provas escritas. A instituição localiza-se na região central de uma cidade de médio porte da região noroeste do estado de São Paulo.

A Escola B foi escolhida por utilizar como metodologia de ensino a Pedagogia de Projetos, método onde os alunos escolhem um determinado tema de seu interesse e o tutor passa a trabalhar os conteúdos dentro da perspectiva e interesse dos alunos. A instituição funciona em período integral, além disso, realiza assembleias quinzenais para discutir e definir as regras da escola com todos os alunos $e$ funcionários; não há salas de aula e os alunos se organizam em grupos para desenvolver os projetos em mesas distribuídas no pátio da escola; as avaliações consideram a singularidade de cada indivíduo e buscam desenvolver habilidades múltiplas, sendo compreendidas como parte integrante e intrínseca ao processo educacional. Atualmente estão matriculados 85 alunos no Ensino Fundamental. A escola se caracteriza como particular, mas seus alunos não pagam mensalidades, é mantida por doações de empresas e associados e localiza-se na periferia da mesma cidade da escola A. Ambas são dirigidas por entidades religiosas ligadas à igreja católica.

\section{Participantes}

Foi acompanhado o trabalho de duas professoras (uma em cada instituição), por meio de observações. Uma é educadora de uma turma de 25 alunos do terceiro ano do Ensino Fundamental I na escola A e a outra atua como tutora de projetos na escola $B$ de um grupo de cerca de 8 alunos. Os alunos das duas turmas tinham idades entre 8 e 9 anos.

Participaram da pesquisa dez professores que responderam à uma entrevista estruturada, sendo seis da escola A e quatro da Escola B. Dos dez docentes, nove são do sexo feminino e um do sexo masculino, encontrando-se na faixa etária entre 27 e 51 anos. Todos possuem nível superior completo, sete deles possuem pós-graduação sendo dois em psicopedagogia, um em psicopedagogia e neuropsicopedagogia e um em educação especial; três professores não especificaram.

\section{Instrumentos}

Para conhecer a concepção de autonomia, regras, sanções e estratégias de resolução de conflitos, os dez docentes que aceitaram colaborar com a pesquisa, responderam à uma entrevista estruturada que coletou dados a respeito da formação e atuação profissional e investigou, por meio de nove questões, o que pensam sobre conflitos e regras, além de nove situações hipotéticas de conflitos entre as crianças na escola, em que os mesmos deveriam apontar sua atuação diante de cada conflito e justificá-la, com o objetivo de avaliar a concepção dos docentes sobre tal temática.

Tais situações de conflito foram retiradas do artigo de Pereira, Marques e Jusevicius (2012), que compõem os nove tipos de motivos dos conflitos encontrados nas escolas segundo Licciardi et al. (2011), que são: a) Ação 
provocativa: tem como característica comportamentos propositais de mexer sem a permissão, ou ainda manifestações verbais com a intenção de irritar. b) Ação provocativa não intencional: é definida como ações que começam sem a intenção de irritar, mas persistem a partir da reação do outro. c) Agressão física: se define como todos os comportamentos impulsivos que envolvem algum tipo de ação física ou ameaça de agressão, como bater ou empurrar. d) Agressão verbal: caracteriza-se por manifestações verbais diante de alguma insatisfação, frustração ou raiva que insulta ou magoa o outro. e) Disputa: se caracteriza pela briga por objetos, espaços, atenção do adulto ou posições em jogos. f) Exclusão: dá-se quando se exclui ou ignora a participação do outro das relações ou das atividades. g) Responsabilidade objetiva: caracteriza-se pela dificuldade dos alunos considerarem a intenção alheia, julgando o comportamento de um colega como uma atitude provocativa, agressiva ou de exclusão, fato que gera conflitos entre as partes. h) Violação de regra: consiste na desobediência a uma norma imposta, regra acordada ou a uma demanda do adulto. i) Delação: se caracteriza por acusar ou contar ao professor o descumprimento de uma regra.

\section{Procedimento}

Para darmos início à pesquisa, que foi aprovada pelo Comitê de Ética em Pesquisa (CEP) sob o parecer 788.190, protocolo CAAE d no 33932714.1.0000.5466, solicitamos a autorização da Direção de ambas as escolas. As observações foram realizadas durante os meses de Março, Abril, Maio e Junho de 2016, primeiramente na escola $A$ e posteriormente na escola $B$, por um período de três horas diárias na sala de aula da escola $A$ e no pátio da escola $B$, completando um total de 30 horas de observação em cada instituição.

As observações permitiram identificar os conflitos interpessoais mais recorrentes e quais as intervenções utilizadas pelos alunos e professores para tentar mediar essas situações; o modo como os professores agiam no sentido de orientar a resolução de conflitos pelos próprios alunos; como as regras eram construídas e se todos as cumpriam; como eram as relações entre alunos e professores e entre os próprios alunos (baseadas no respeito unilateral ou no respeito mútuo) e se as atividades em sala promoviam a cooperação. Quanto a entrevista, os docentes a responderam de forma escrita devido à falta de disponibilidade dos mesmos para responderem as perguntas de forma gravada.

\section{RESULTADOS}

As observações, juntamente com as análises das entrevistas realizadas com os dez professores das duas escolas investigadas nos indicam que o conflito é inerente às relações escolares. Porém, notamos discrepâncias tanto nas observações quanto nas respostas dos professores da Escola A e das professoras da escola B.

Com relação as observações realizadas no terceiro ano da escola $A$, a primeira impressão foi de uma turma aparentemente tranquila onde as crianças, praticamente, não se comunicavam durante as atividades. A professora, em determinados dias, organizava as carteiras de maneiras diferentes, em círculo, duplas e grupos, fugindo do padrão tradicional de fileiras. Entretanto, tais mudanças não colaboraram para aumentar a interação entre as crianças, visto que era cobrado constante silêncio pela docente. Não eram recorrentes situações conflituosas nessa turma, mas quando aconteciam, em sua maioria, eram por conta da dificuldade de algumas crianças em aceitar as regras dos jogos nas aulas de Educação Física ou por conta de ações provocativas.

Dos poucos conflitos presenciados em sala de aula, foi possível observar que a professora procurava resolvê-los com punições, como deixar os envolvidos sem recreio, ou procurava contê-los direcionando os alunos à Direção, ou usava de ameaças com ocorrências e bilhetes aos pais. Os alunos não eram incentivados a resolverem os próprios conflitos, contudo, o que mais nos chamou a atenção durante as observações foi o comportamento das crianças em constante silêncio. Vinha (2000, p.350) destaca que:

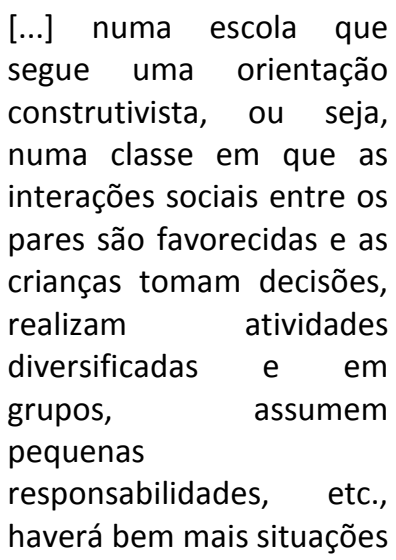


de conflitos do que na escola tradicional, onde os alunos, em geral, interagem muito pouco uns com os outros, cabendo ao professor resolver os problemas e tomar decisões. Portanto, desconfiem de uma classe de crianças silenciosas.

Com relação as regras, observamos que, por ser uma instituição de grande porte, as normas gerais da escola eram elaboradas pelos docentes e gestão. Já as regras de convivência entre as crianças eram elaboradas no início do ano por cada professora com sua respectiva turma, por meio dos "combinados da turma".

Na escola B, foi observado o trabalho de uma tutora que acompanhava o desenvolvimento do projeto de um grupo com oito alunos. A tutora auxiliava 0 grupo a montar $o$ projeto e $o$ cronograma de execução a partir dos interesses das próprias crianças. Para desenvolver o projeto os alunos realizavam pesquisa em livros, internet e pesquisa de campo. Para as reuniões e desenvolvimento das atividades escritas eles se organizavam em grupos nas mesas distribuídas pelo pátio da escola. A proposta pedagógica da escola tem como função potencializar o desenvolvimento de todas as capacidades, de modo a tornar o ensino mais humano e ético. Os conteúdos de cada disciplina são analisados referentes a procedimentos não do ponto de vista de uma aprendizagem mecânica, mas a partir do propósito fundamental da educação, que é fazer com que os alunos construam instrumentos para analisar, por si mesmos, os resultados que obtém e os processos que colocam em ação para atingir as metas a que se propõem. Desta forma, os planejamentos dos conteúdos são inseridos num sistema de ensino que visa a realização de projetos realizados pelos próprios alunos, de acordo com sua singularidade.

Os conflitos mais recorrentes nessa escola referiam-se a disputa de mesas e divergência de opiniões, onde as tutoras (professoras) buscavam resolvê-los por meio de conversas com os envolvidos e às vezes encaminhando os mesmos à Direção. Observamos também, que nas ocorrências de conflitos entre os pares, as próprias crianças tentavam resolvê-los e a ajuda do adulto não era solicitada com muita frequência.
Quinzenalmente ocorriam as assembleias na instituição onde toda a comunidade escolar, gestores, docentes e principalmente os alunos colocavam em pauta os problemas ou conflitos cotidianos que precisava de uma intervenção e todos podiam sugerir possíveis soluções para os problemas apresentados. Posteriormente, era realizada uma votação diante das soluções propostas para decidir as que julgavam mais adequadas. Todo desenvolvimento da assembleia era mediado pelos próprios alunos eleitos pelo grupo com prefeitos e vereadores.

Com relação às entrevistas realizadas, os seis professores entrevistados na escola A acreditam que a maioria dos conflitos que se deparam, tanto entre os alunos como entre professores e alunos, estão relacionados ao desrespeito nas relações interpessoais, como atitudes que envolvem empurrões, gritos e insultos. Relataram que as desavenças ocorrem por atitudes do aluno como falta de respeito, de limites impostos pela família e de maturidade, julgando os conflitos construtivos apenas quando é possível tirar algum proveito da situação. Apenas uma resposta indicou o valor construtivo do conflito voltado para a oportunidade de se trabalhar valores.

Nas entrevistas realizadas na escola $B$, as quatro professoras que participaram da pesquisa acreditam que os conflitos ocorrem por sermos seres humanos diferentes, que convivem em sociedade, onde cada um tem sua personalidade e forma de pensar. Apontaram que são situações sempre construtivas, pois dá às crianças a oportunidade de aprenderem valores e ouvirem diferentes opiniões e acreditam que são formas também de aprendizagem importantes para a formação moral dos alunos.

À vista de tais exemplos é possível observarmos que os conflitos mais relatados pelos docentes da escola $A$, tanto entre os alunos, como entre professores e alunos referemse à falta de respeito por parte dos discentes. $\mathrm{Na}$ escola B, é citado por uma das professoras a importância de orientar os alunos para formá-los ética e moralmente; salientam as regras, mas estas são estabelecidas por alunos e professores, e as divergências indicam que as crianças estão em desenvolvimento. As docentes da escola B possuem, portanto, ações e perspectivas mais favoráveis ao desenvolvimento da autonomia dos alunos, diferentemente da escola $A$, onde as docentes não reconhecem a importância dos 
conflitos nas relações e na formação social e moral dos indivíduos.

Com relação as situações hipotéticas de conflitos, houve uma similaridade nas respostas dos professores da escola A em tomar para si a resolução do conflito, que deveria pertencer à criança, tendo a conversa como principal recurso para resolver as situações e usando como argumento essencial "pedir para o aluno colocarse no lugar do outro". Um dos professores apontou que pediria para a criança provocada escolher a punição do amigo privando-o de uma atividade que ele goste. Na escola $B$ as respostas foram similares à escola $A$ e, na fala das docentes, também prevaleceram atitudes como conversar com os envolvidos, pedir para que se coloquem no lugar do outro.

Prevaleceram, assim, atitudes que tentassem conter ou evitar as desavenças, onde poucas vezes as crianças foram estimuladas a resolverem seus próprios conflitos, sendo o professor a tomar a frente da situação, buscando resolvê-los pelos seus alunos por meio de lições de moral, as vezes obrigando as crianças a um determinado comportamento, como pedir desculpas, castigando-os com a privação de algo que gostam e comunicando o ocorrido às famílias ou à direção.

Sendo assim, os resultados obtidos nas entrevistas indicam que a maioria das ações dos docentes da escola $A$ frente aos conflitos não favorecem o desenvolvimento moral dos alunos. Isso acontece, muitas vezes, por tomarem os conflitos para si e resolvê-los pelas crianças ou por utilizarem de sua autoridade para impor uma solução e obrigar os alunos a determinada atitude, não reconhecendo a importância dos conflitos nas relações interpessoais e na formação moral. Apesar da maioria das ações e perspectivas das professoras da escola B serem mais favoráveis ao desenvolvimento da autonomia, foi possível constatar, mediante análise dos relatos, que também existem práticas coercivas e, algumas vezes, não é dado aos alunos a oportunidade de resolverem seus próprios conflitos. Contudo, acreditamos que as assembleias, os projetos e o ambiente democrático promovido pela escola, permitindo que os alunos trabalhem em grupo, são fatores determinantes para que tenham um ambiente mais recíproco, onde praticamente não ocorrem situações de agressividade e violência.

\section{DISCUSSÃO}

Foi possível observarmos que na escola $A$ os conflitos mais recorrentes estão ligados a situações de agressão e violência que tendem a ser resolvidos pelos docentes por meio de conversas com os envolvidos, deixar os mesmos sem intervalo, comunicados à direção, ocorrências e bilhetes aos pais via agenda. Vinha (2000) destaca, no entanto, que cabe ao professor tentar resolver os conflitos que ocorrem na escola da melhor maneira possível, não os deslocando para os pais ou responsáveis que não tiveram a mesma formação que o docente. Já na escola $B$, os conflitos mais recorrentes se dão pela disputa por mesas e divergências de opiniões. Não há relatos de agressões e os conflitos nessa escola são resolvidos, em sua maioria, por meio de conversa com os envolvidos e raramente com comunicados à direção.

Vale ressaltar que os conflitos tidos como "divergência de opiniões" referem-se aos diferentes pontos de vista colocados pelos alunos na realização dos projetos. Tal discordância também pode ser considerada como um conflito, porém, são situações que tendem a desenvolver a autonomia por favorecerem a coordenação de diferentes pontos de vista e perspectivas além de favorecer uma escuta ativa à opinião dos demais colegas.

Com relação as assembleias que acontecem quinzenalmente na escola $B$, Vinha e Tognetta (2007) consideram que são situações em que se tem a oportunidade de se transmitirem valores como a participação, a cooperação, o diálogo e a autonomia. São, portanto, uma possibilidade cooperativa de resolução de conflitos, uma oportunidade para que as crianças e adolescentes se sintam pertencentes ao grupo e responsáveis por este, pois, como apontado por Vinha (2000, p.257), "não se combinam todas ou as principais regras apenas no começo do ano, mas somente após as crianças sentirem a necessidade delas existirem", e as assembleias são excelentes oportunidades para que as crianças discutam, com periodicidade princípios e atitudes e construam regras de regulação coletiva e propostas de resolução de problemas.

Quanto ao pedido de desculpas, utilizado como estratégia de mediação por muitos dos docentes entrevistados, é possível considerá-lo fundamental para reestabelecer os laços rompidos, mas, apenas quando o 
arrependimento for sincero e houver um real desejo de redimir o comportamento ou atitude que causou o conflito (VINHA, 2000). Pedidos forçados de desculpa geralmente são insinceros e operam contra o descentramento e o desenvolvimento de empatia. Já o pedido espontâneo é capaz de reestabelecer o elo rompido, podendo ser decorrente de uma relação de respeito mútuo.

Em ambas as escolas houve uma similaridade nas estratégias de resolução dos conflitos apresentados, em que prevaleceu o diálogo como principal estratégia de intervenção citado pelos docentes. Porém, na escola $A$, observamos também mediações de caráter coercitivo e ações que tendiam a reforçar a heteronomia das crianças visto que, na maioria das vezes, o professor tomava o conflito da criança para si ou tentava contê-lo de forma rápida, não intervindo para que ela tivesse a oportunidade de resolvê-lo, demonstrando não reconhecerem a importância dos conflitos nas relações e formação moral dos indivíduos. Nesse ambiente, pudemos observar alunos mais agressivos que tendiam a resolver suas desavenças de forma impulsiva não considerando os sentimentos dos demais.

Já na escola B, os alunos conseguiam resolver seus conflitos com mais autonomia e não solicitavam com tanta frequência a ajuda do professor. Nesse ambiente não observamos situações de agressividade física e verbal entre os indivíduos, a ajuda da Direção era solicitada em raras vezes. Além disso, as assembleias quinzenais colaboravam para que os professores conhecessem melhor seus alunos e estes se conhecessem, para que as regras fossem elaboradas e reelaboradas sempre que preciso, para que os conflitos fossem discutidos com soluções negociáveis e para que a democracia e o respeito mútuo tornassem-se princípios norteadores das relações interpessoais.

\section{CONCLUSÃO}

Com a análise dos dados obtidos na pesquisa, via observação e entrevistas com os professores, concluímos que os docentes se deparam constantemente com dificuldades, conflitos e problemas repentinos em seu trabalho diário e a maneira que lidam com tais situações interferem na construção da autonomia moral das crianças, mas nem todos o fazem em direção à autonomia.
Notamos que mesmo em um ambiente que estimula as relações de cooperação, a autonomia moral dos alunos não pode ser conquistada sem o comprometimento e estudo constante do professor. Dessa forma, os educadores precisam conhecer como se dá o desenvolvimento moral infantil para lidarem melhor com as situações de conflito, encarandoas como oportunidades para que as crianças construam valores que visem o alcance da moral autônoma. Esta só se desenvolverá a partir de relações de reciprocidade e respeito mútuo.

Visto que em ambas as escolas, para a maioria dos conflitos apresentados a principal estratégia de resolução utilizada pelos docentes é a conversa, cabe enfatizar que a aprendizagem da resolução de problemas e desavenças por meio do diálogo não se dá de uma hora para outra, ou seja, é a partir das situações conflituosas, havendo a intervenção e orientação adequada por parte do professor, que as crianças aprenderão a substituir a imposição e agressão pelo diálogo no processo de resolução dos conflitos (VINHA, 2000).

A escola, como em toda a sociedade, precisa da elaboração e do cumprimento de regras, de normas que norteiam o funcionamento, as relações, a convivência, a cooperação, que possibilitam o diálogo e as trocas sociais. Mas a grande quantidade de regras impostas não significa que as mesmas se baseiam em princípios que as sustentem.

É importante, que as crianças estejam envolvidas na tomada de decisões e estabelecimento de regras em sua classe, para que possam contribuir na construção de uma atmosfera de respeito mútuo e cooperação e que criem as regras conforme sentirem necessidade da existência das mesmas, e não apenas no início do ano como forma de prevenção dos conflitos. Para isso, precisam estar inseridas em um ambiente onde o autoritarismo do adulto seja minimizado e que dê condições para que aprendam a resolver seus conflitos de forma respeitosa, experienciando situações de respeito mútuo, justiça, cooperação, reflexão e tomada de decisões, para que, aos poucos, ela se autodisciplinem e regulem seu comportamento, para que não se pautem mais na obediência exterior e passem a levar em consideração os sentimentos e pontos de vista do outro.

$\mathrm{Na}$ perspectiva piagetiana $\mathrm{o}$ adulto coercitivo orienta a criança para uma moralidade de obediência, enquanto o cooperativo encoraja 
a autorregularão da mesma por meio de princípios autoconstruídos por ela própria. Portanto, em ambientes onde prevalecem relações de respeito mútuo e reciprocidade, as crianças terão mais chances de construir estratégias mais, assertivas, justas e respeitosas para resolverem seus conflitos e alcançar a autonomia. Dessa forma, cabe ao educador ter ampliação de conhecimento e compreensão da existência de diferentes valores, socialização e integração, saber que há diferentes formas de entendimento, compreensão e resolução de conflitos uma vez que a maneira como o docente age sobre o processo de educação do indivíduo é uma escolha que traz consequências em longo prazo.

Infelizmente, na maioria das escolas prevalece o ambiente sócio moral coercitivo, exigindo que as crianças sejam submissas e conformistas. Mesmo os professores bemintencionados sentem que é de sua responsabilidade ser autoritário em sala de aula, oferecendo regras aos comportamentos e atitudes das crianças buscando discipliná-las pelo uso de recompensas e punições (DEVRIES E ZAN, 1998). Tais estratégias são, de fato, efetivas, mas o uso dessa autoridade pelo adulto gera consequências negativas.

Constatamos, portanto, que as relações interpessoais estabelecidas na escola proporcionada pelos docentes influenciam na formação do ambiente sócio moral e consequentemente no desenvolvimento da moral do aluno, porém percebemos que a educação moral não está presente de forma efetiva nas escolas, deixando a desejar quanto ao ambiente promovido e as relações que impõe. Sendo assim, a equipe escolar (gestores e docentes) precisa dar relevante atenção à qualidade das relações que promove no ambiente educacional e assumir seu percentual de responsabilidade sobre a educação moral de seus alunos.

Ressaltamos que não adianta tentarmos ensinar a moralidade, pois ela é construída a partir da interação do sujeito como o meio em que vive pelas experiências com as pessoas e situações. Sendo assim, o educador precisa compreender que não é possível uma criança ser autoconfiante se vivencia sucessivas situações em que fracassa, nem dar valor a si mesma sendo sempre desvalorizada ou criticada. "Não se aprende a respeitar sendo frequentemente desrespeitada, muito menos a dialogar ou superar-se sendo constantemente censurada" (VINHA, 2000, p.286).

Consideramos, por fim, que o tema do presente estudo é significativo e atual dado o número crescente de educadores que se deparam com as mais variadas situações de conflito dentro do ambiente educacional. Esta pesquisa apresenta, portanto, resultados de um estudo que enfocou especificamente situações de conflitos entre crianças dos anos iniciais do Ensino Fundamental que consideramos de suma relevância para o estudo dos professores e consequente para o desenvolvimento moral autônomo de seus alunos.

\section{REFERÊNCIAS}

DEVRIES, R.; ZAN, B. A ética na educação infantil: o ambiente sociomoral na escola. Tradução de Deyse Batista. Porto Alegre: Artmed, 1998.

LEME, M. I. S; TOGNETTA, L. R. P.; VICENTIN, V. F. Quando os conflitos nos pertencem: uma reflexão sobre as regras e a intervenção aos conflitos na escola que pretende formar para a autonomia. Campinas: Mercado de Letras, 2013.

LICCIARDI, L. M. S. et al. Conflitos entre pares: percepção de professores e alunos de 50 ano. Revista Múltiplas Leituras, Franca, v. 4, n. 2, p. 69-84, jul./dez. 2011. Disponível em: https://www.metodista.br/revistas/revistasims/index.php/ML/article/viewFile/2856/2907. Acesso em: 27 jun. 2016.

NUNES, Antônio Ozório. Como restaurar a paz nas escolas: um guia para educadores. São Paulo: Contexto, 2011.

PIAGET, Jean. O juízo moral na criança. São Paulo: Summus, 1932/1994.

PEREIRA, P.; MARQUES, C. A. E.; JUSEVICIUS, V. C. C. A ação dos professores diante dos conflitos entre alunos. Revista Intellectus, Campinas, ano 9, n. 25, $2012 . \quad$ Disponível em: http://revistaintellectus.com.br/DownloadArtigo. ashx?codigo=312. Acesso em: 18 jul. 2016.

TOGNETTA, L. R. P. A formação da personalidade ética: estratégias de trabalho com afetividade na escola. Campinas: Mercado de Letras, 2009.

VINHA, T. P.; TOGNETTA, L. R. P. Quando a escola é democrática: um olhar sobre a prática das 
regras e das assembleias na escola. Campinas:

Mercado de Letras, 2007.

VINHA, T. P. O educador e a moralidade infantil uma visão construtivista. 3. ed. Campinas: Mercado de Letras, 2000.

Recebido para publicação em: 09/08/2017

Revisado em: 21/09/2017

Aceito em: 27/09/2017 